\title{
Research on Filling Mining with Fly Ash-based Cement Materials
}

\author{
Weixin Chen ${ }^{1, a^{*}}$, Fengyi $\mathrm{Li}^{2, \mathrm{~b}}$, Xianhua Guan \\ 3,c , Shiming Liu ${ }^{4, d}$, Mingchao Fu ${ }^{5, e}$ \\ ${ }^{1}$ Mining Research Institute, Heilongjiang University of Science and Technology, harbin, China \\ ${ }^{2}$ Mining Research Institute, Heilongjiang University of Science and Technology, harbin, China \\ ${ }^{3}$ Mining Research Institute, Heilongjiang University of Science and Technology, harbin, China \\ ${ }^{4}$ Mining Research Institute, Heilongjiang University of Science and Technology, harbin, China \\ ${ }^{5}$ Coal Industry Bureau of Shandong Ningyang,Shandong, Taian,China \\ a287760448@qq.com, bkyyjylfy@163.com , c450655485@qq.com, Ilsm276@qq.com , \\ e414480812@qq.com
}

Keywords: Fly-ash cementing materials; bag-filling; filling effect

Abstract. In order to prevent surface movement and release "three under" coal, the new fly-ash cementing materials were utilized to take industrial test in Taoshan mine NO.3 colliery 95\# coal-seam gob. The filling slurrys were transported into the filling bags in gob along the pipeline, taking away the pillar and template when filling materials were hard enough to support the roof, a great deal of filling bags formed filling strip, which replaced the protective pillar. The test results show that the compressive resistance of filling materials will reach $0.87 \mathrm{MPa}, 2.36 \mathrm{MPa}, 3.38 \mathrm{MPa}$ and $6.38 \mathrm{MPa}$ when 8hours,1day,3days and 28days, and the initial setting time is 94 minutes. Since the method is utilized in filling mining of Taoshan mine, the recovery ratio of coal raises effectively, the roof have no breakdown, the surface have little subsidence.

\section{Introduction}

With the continual exploitation of coal resources, such as the old coal bases Heilongjiang province, the problem of which the depletion of coal resources has became more and more apparent, and which has became the bottlenecks of socioeconomic sustainable development in the old coal mining industry.Industry square, railways, towns and the protected coal pillar under water, all of which have turned into a considerable number of high-quality coal resources. However, the coal exploitation technology of how to protect the overburden from destroying and make the surface have no significant disturbance, which were the important technical guarantee that mining these retention coal, extending the mine service life and maintaining the socioeconomic sustainable development in the old coal mining[1].

Filling systems and processes are designed according to the properties of the filling material. At present, the effect of high water-cement ratio and paste material filling technology are obvious. Solid high water cement ratio 2.5:1 material, divided into two kinds A and B, so need two equipment pulp and double pipeline pump, mixed into a slurry filling in filling locations. Paste materials generally comprise a solid mass of the total weight of the material 75 to $88 \%$, resulting in poor fluidity of the slurry, generally. The slurry made in ground is pumped using the pressure pump into filling locations. Fly ash based cements is water-cement ratio of 0.85 to 1.25 , and therefore better mobility. The slurry pulped in the ground is pumped by a single pipeline. The filling system achieved good results in goaf of Qitaihe Taoshan 93 coal seam, got a more mature fill mining techniques. 


\section{Fly Ash-based Cement Material}

Composition and Characteristics of Materials.Fly ash-based cement materials were developed by the mining research institute, Heilongjiang university of science and technology, filling materials are made of main materials and auxiliary materials. Main materials include fly ash, waste water, waste rock and other solid materials; auxiliary materials include HHJ series activator, KYY-S series accelerator, KYY-ZH series of early strength retarder, sulfur cement, lime, and gypsum.

The mechanism of exciting early activity for fly ash is mainly to destroy the internal vitreous network structure of fly ash, so that broken key depolymerization and generate reactive monomer or dimer structure, promote fly ash to participate the early hydration reaction of cement paste.

The method for activating fly ash activity by chemical agents generally includes bases, acids, and salts. Although strong acids and bases classes can stimulate the activity of fly ash very well, that it will weak the effect of cement gel greatly, and reduce the strength of the material. This paper utilizes weak acid alkali (HHJ-1 and HHJ-2) and sulfate (HHJ-3 and HHJ-4) as the fly ash activator. In the past, the activation was later than the solidification of additives and fly ash, and the exciting effect was slow. In order to excite the activity of fly ash quickly, the method of activation in this paper is that mixing fly ash and activator with water, placing a certain time, and then adding the other agents, at last, filling cemented slurry will be obtained.

That characteristic include: slurry can be achieved gravity conveyor within 90minutes; the slurry begins to solidify after 90minutes, without shrinkage after final setting backfill and have micro-expansion with the curing period; good stability, since the material contains a large number of fly ash, fly ash participates hydration reaction along with ongoing age, producing more and more hydration products, which will make the internal structure of the material get more uniform, dense and stable; stronger resistance to stress, after the final setting, the compressive strength of filling body is 0.8 1.2 MPa after 8hours, $1.5 \sim 3.0 \mathrm{MPa}$ after 24 hours, $2.0 \sim 4.0 \mathrm{MPa}$ after 72 hours, $4 \sim 7 \mathrm{MPa}$ after 28days.

Impact on the Material Properties of the Activation Time. The activation time of fly ash is about 2 hours to 8 hours in the filling mining site. Activation time has a significant impact on compressive strength of the materials, compressive strength is more higher when activation time is more longer, and the initial setting time is more shorter, that because if the activation time of fly ash is extended, there will be formed more gel, which promotes hydrated for material. The effect of activation time on the compressive strength and setting time is shown in Fig. 1.
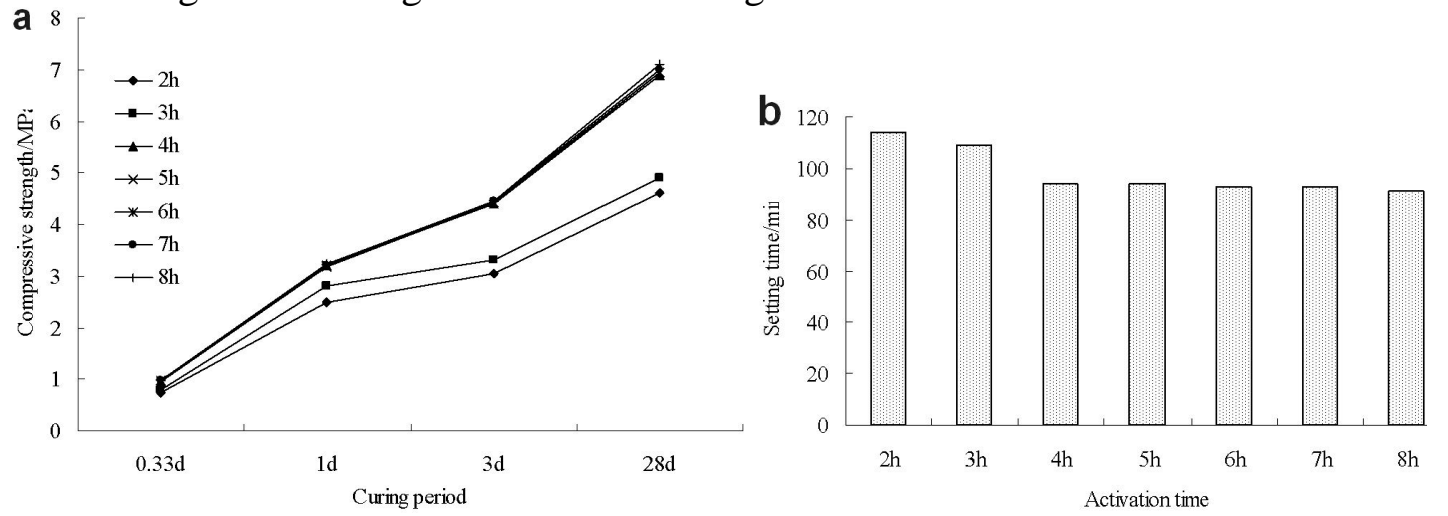

Fig.1. (a) effect of activation time on the compressive strength; (b) effect of activation time on setting time

Impact on the Material Properties of Water-solid Ratio. Water-solid ratio of filling material is generally taken to be 0.85 to 1.25 , fly ash mortar after activation is not frozen, mix with other additives, the initial setting time is generally $90 \sim 145$ minutes, the time between final setting time and setting time is generally not more than 30minutes. The uniaxial compressive strength of 8hours is not less than $0.7 \mathrm{MPa}$, the uniaxial compressive strength of 3days is not less than $2 \mathrm{MPa}$, and the uniaxial compressive strength of 28 days is not less than $5 \mathrm{MPa}$. Compressive strength and initial setting time in different water-solid ratio is shown in Fig. 2. 

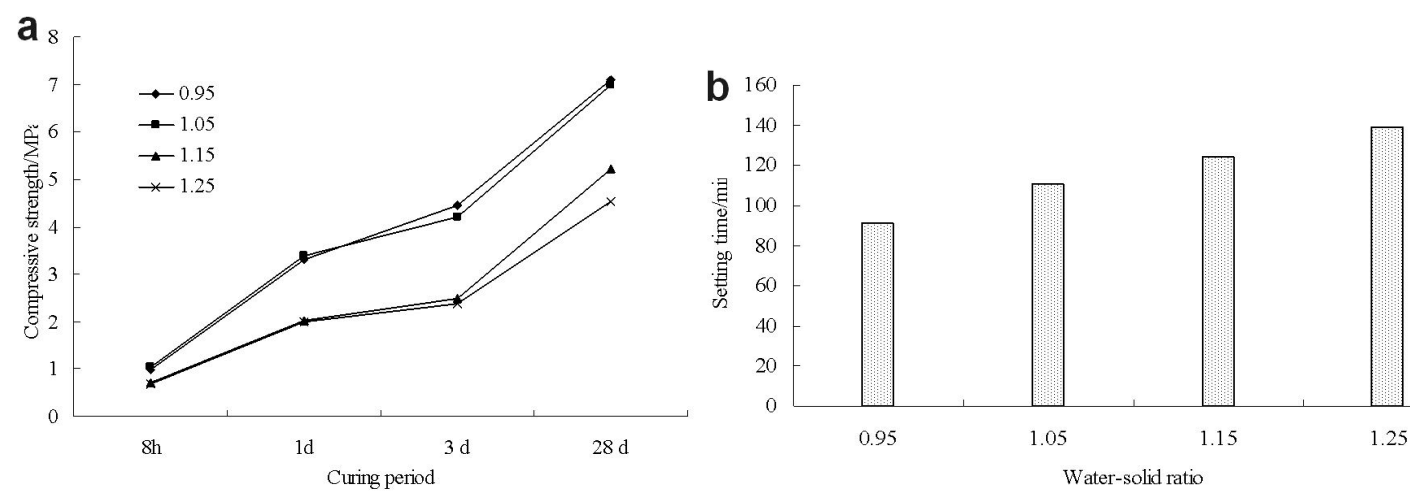

Fig. 2. (a) effect of water-solid ratio on the compressive strength; (b) effect of water-solid ratio on setting time

\section{Mining Face Overview}

The development plan in Taoshan mine 93 coal mining face is plate and inclined shaft, which include two shafts. The main shaft is track down, which is used to inlet air, lift coal, lift gangue and transport. The auxiliary shaft is used to return air and walk. The mining method is retreating long-wall and blast dropping coal.

Filling mining experiment is worked in Taoshan mine 93 coal mining face. Roof control method is to leave wooden pillars to support the roof in the face of worked out section, the diameter of wooden pillars is birch poles which is not less than $140 \mathrm{~mm}$ and their spacing and row spacing are $1.0 \mathrm{~m}$. The average seam thickness of $93 \mathrm{coal}$ is $0.9 \mathrm{~m}$, the structure is simple, roof and floor rock are fine-grained sandstone and silt, fine-grained sandstone interbedded. The stope width is $26 \mathrm{~m}$, strike length is 680m.Comprehensive column is shown in Fig. 3.

\begin{tabular}{|c|c|c|c|c|c|}
\hline Columna & Layer & Depth/m & Thickness $\mathrm{m}$ & Rock name & Description \\
\hline & 45 & 215.10 & 4.88 & Fine sandstone & \\
\hline & 46 & 219.05 & 3.71 & Siltstone & \\
\hline & 47 & 222.95 & 3.66 & Fine sandstone & \\
\hline & 48 & 225.05 & 1.97 & Siltstone & \\
\hline & 49 & 225.07 & 0.02 & Coal & \\
\hline & 50 & 225.27 & 0.20 & Fine sandstone & \\
\hline & 51 & 226.27 & 1.00 & Coal & $95 \#$ \\
\hline & 52 & 227.07 & 0.80 & Siltstone & \\
\hline & 53 & 227.67 & 0.60 & Coal & 95\# underside \\
\hline & 54 & 229.47 & 1.80 & Siltstone & \\
\hline & 55 & 229.59 & 0.12 & Coal & \\
\hline & 56 & 230.69 & 1.10 & Siltstone & \\
\hline & 57 & 231.79 & 1.10 & Coal & $96 \#$ \\
\hline & 58 & 236.06 & 4.27 & Arenaceous-shale & \\
\hline & 59 & 238.40 & 2.34 & \begin{tabular}{|l|} 
Fine sandstone \\
\end{tabular} & \\
\hline
\end{tabular}

Fig. 3. comprehensive column

\section{Filling System}

Pulp Pumping System and Process.Filling pulping system is mainly composed of two sets of mixing equipment (activated fly ash slurry into the mixing equipment and mixing equipment, the former six times the volume of the latter). In order to ensure the continuity of slurry, slurry mixing device is two at least. Filling pulping system is shown in Fig. 4.

Before filling, mix fly ash, water and activator into activation of mixing device for 10 to 20 minutes, and then place 2 hours to 8 hours. Stir about 5 minutes every 30minutes to 60 minutes to prevent the slurry sink to the bottom.

When activation of the fly ash slurry was pumped through a pump to all mixing pulp equipment, and then one of the devices are added to the slurry cement, lime, gypsum, KYY-ZH series early strength retarder, KYY-S series speed coagulant, mixing 5 to 15 minutes, Opening the discharge valve, Slurry 
was pumped through the pipeline to $160 \mathrm{~mm}$ special plastic bags filled underground. At the same time, sulfur cement and other additives were added in another mixed device, when the slurry in first mixing device pump finished, it can be stirred into slurry for the second upon in the slurry pumping device, and so complete the alternating cycle of pulp to achieve semi-continuous pulping [2]. When all of slurry using slurry transport slurry was pumped from mixed device, the remaining slurry is pushed out by the pressure of wind.

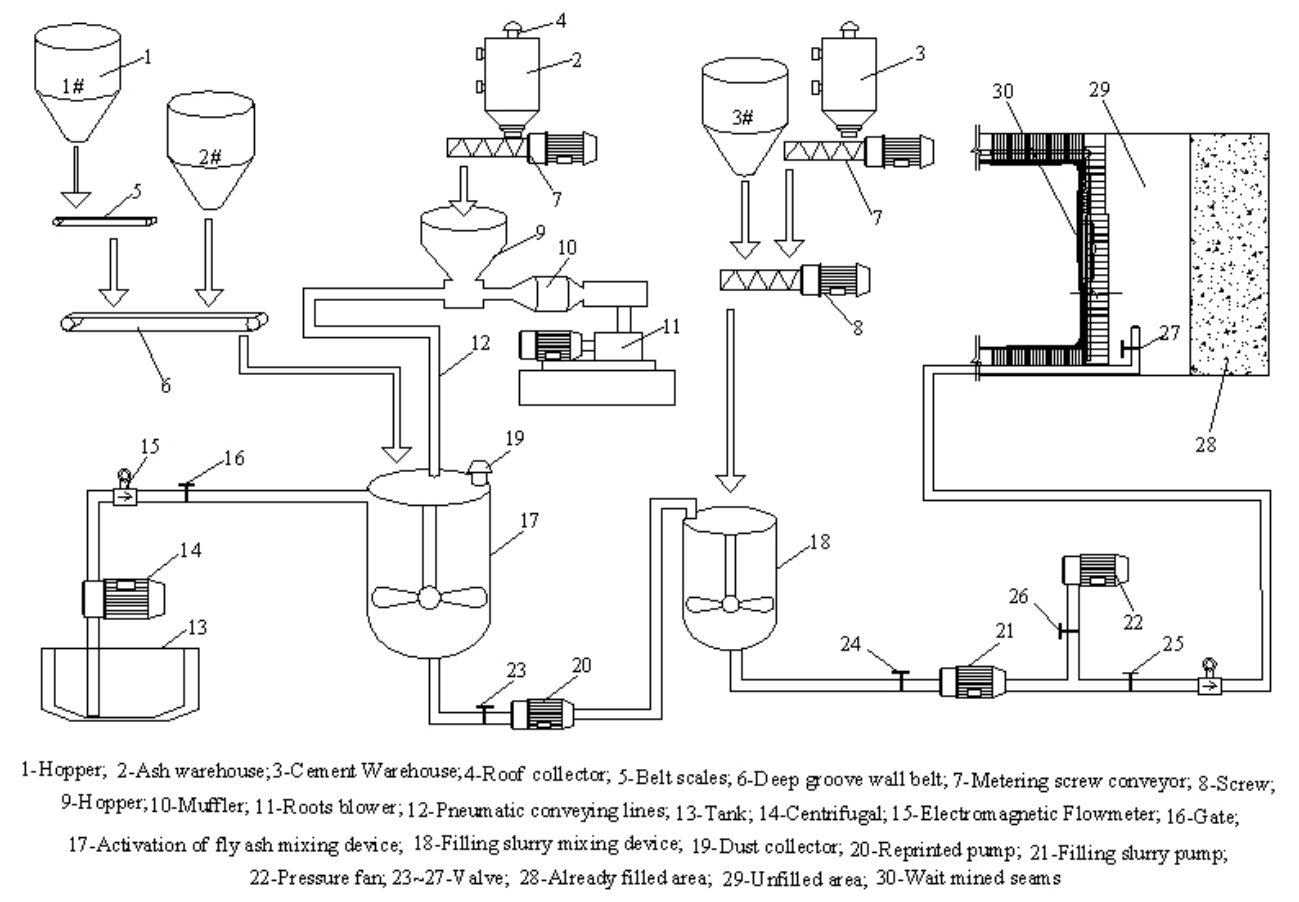

Fig. 4. filling pulping system

Transportation System.Pipeline system consists of two parts activation of pulping to transport the lane line and transportation lane to pack bags line. Piping used in the first paragraph are special delivery pipe, pipe diameter is $160 \mathrm{~mm}, 12.5 \mathrm{~mm}$ thick. Wall thickness deviation of $10 \%, 2 \%$ out of roundness, the tensile strength of $15.0 \mathrm{MPa}$, tensile elongation is $380 \%$, average $3.2 \times 104 \Omega$ outside surface resistance, surface resistance within the average $1.5 \times 104 \Omega$, average time of $2.0 \mathrm{~s}$ with flame combustion on the alcohol burner, a maximum time of $2.3 \mathrm{~s}$ with flame combustion, flameless combustion time average $0.4 \mathrm{~s}$, flameless combustion time maximum $0.5 \mathrm{~s}$, all pipe with flange connection. The second section of the pipeline by 3 inches soft belt conveyor filling slurry filling, soft belt, 3 inches use special coupling connection between working face end to pack using 4 inches soft packing belt, with 4 inches special coupling connection, special arrangement because of filling body, continuously extended filling soft belt during filling, enter the working face with a soft belt extended to connect. In addition, there is spare packing line to prevent pipeline blocking damage; slurry mixing pool can't pack to face in time, and so piping layout is shown in Fig.5.

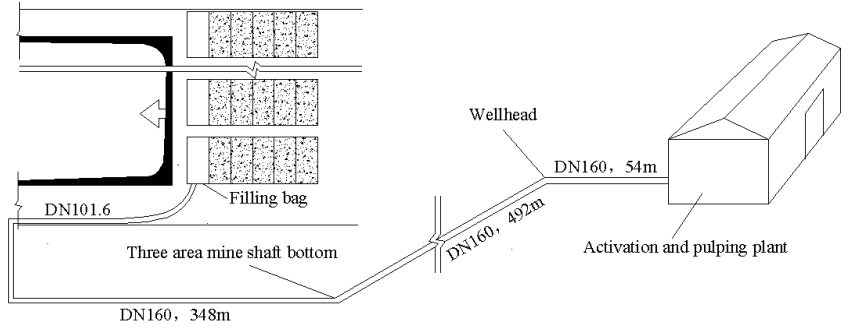

Fig.5. the layout of filling pipe

Filling Bags and Templates Pillar.Filling bag is made with water resistant polymer material , have the properties of high strength, anti-static and flame retardant. The sizes of filling bags can be adjustment vary, according to the coal geological conditions to adapt the practice. 
The packing bags are designed as $5 \mathrm{~m}$ long, $1 \mathrm{~m}$ high and $2 \mathrm{~m}$ wide, according to the length of working face, coal mining filling penetration. Template with polyethylene plastic soft board, which is $1 \mathrm{~m}$ long, $1 \mathrm{~m}$ high, $2 \mathrm{~cm}$ thick, the distance between two templates overlap is not less than $10 \mathrm{~cm}$. Pillar uses birch wood columns, the distance between two pillar is $20 \mathrm{~cm}$.

\section{Filling Method and Program}

Bag filling used in this paper based on the coal mining and coal seam dip angle. Along to strip partially filled based on good roof and floor litho-logic. Layout of filling body using the Strip spacing arrangement in goaf, Filled with strips spaced $2 \mathrm{~m}$, filling rate of about $70 \%$. Gob-side entry retaining was carried out that distance of filling strip and the roadway was no more than $3 \mathrm{~m}$.

It was selected that materials water-solid ratio of 1.2 , ash activation time of $4 \mathrm{~h}$ by geological conditions of goaf. Three eight-hour shifts (filling and repairing in one shift and mining in two shifts) was adopted. Filling system can reach the maximum filling volume of $390 \mathrm{~m} 3$ one time and $117000 \mathrm{~m}^{3}$ of per year. The mining method could mine coal $234000 t$ per year.

\section{Effect Analysis of Bag-filling}

Filling Effect in Field.The inspection was conducted among the 10 underground filling bags into the material days paste selected by random sampling. Take part of the slurry in the down hole of initial and final setting time is measured by vicat apparatus, part into $7.07 \mathrm{~mm} \times 7.07 \mathrm{~mm} \times 7.07 \mathrm{~mm}$ the joint test. Uniaxial compressive strength determined test results with WDS-50A press in the lab after conservation at down hole, which are shown in Table 1. This material performance reaches the expected target in the two aspects of condensation and compressive, which instructions that it can adapt to filling system and filling process.

The rate of supporting pit roof is above $96 \%$ in random 10 days after filling. The remaining $4 \%$ is due to the filling process of filling bags filled with bags full pleated without cause.

Monitoring of the Convergence between Roof and Floor in Filling Area. Three surveyed areas were arranged at away from open-off cut $6 \mathrm{~m}, 30 \mathrm{~m}, 90 \mathrm{~m}$ places. Three measuring points are arranged in each surveyed area. Using ADL2.5 measuring rod observed amount of movement of the roof and floor within a month, the largest was $9.4 \mathrm{~mm}$, the minimum of $8.1 \mathrm{~mm}$, the average amount of movement of $8.6 \mathrm{~mm}$. All the surveyed area closer to the amount of the fastest in $3 \mathrm{~d}$, closer to volume growth has been slowing in $3 \mathrm{~d}$, the roof and floor closer to the speed of measurement points close to zero in $21 \mathrm{~d}$, the measuring point closer to the top floor was not significant change in the volume 90 days, indicating that the roof and floor reached a relatively stable state in the role of filling body [3, 4].

Monitoring of Surface.Observation device is set up in filling areas, observing surface from mining face, the maximum surface subsidence was $20 \mathrm{~mm}$ by measuring eight times in two years, which conform the requirements, it can protect ground buildings without damage [5,6].

Table 1. the average uniaxial compressive strength and setting time.

\begin{tabular}{lllll}
\hline \multicolumn{2}{l}{ The average uniaxial compression strength /MPa } & $\begin{array}{l}\text { The average } \\
\text { initial setting } \\
\text { time/min }\end{array}$ \\
\hline $8 \mathrm{~h}$ & $24 \mathrm{~h}$ & $3 \mathrm{~d}$ & $28 \mathrm{~d}$ & 94 \\
\hline 0.87 & 2.36 & 3.38 & 6.38 & 94 \\
\hline
\end{tabular}

\section{Conclusions}

That the fly ash-based cement filling materials form filling body, which make the early strength growth rapidly, the setting time not only meets the pumping requirements, but also shorts the time to removal the template by solidification in time. 
This filling mining method doesn't need to leave coal protection pillar in "three under" mining, the resource recovery rate is greatly increased by $40 \%$, the effect of reducing the surface sink is obvious, which can provide reference for "three under" mining in the future.

\section{Acknowledgements}

The work was supported by Heilongjiang Province High-tech Industrial Development (non-infor mation industry) special funds (FW12A018).

\section{References}

[1]Fengyi Li, Tan Li, Weiwei Wang. Filling experiment of high-water material in Taoshan coal mine [J],Journal of Heilongjiang Institute of Science and Technology, 2012(5):221-224.

2011(4):1-8.

[2]Guangming Feng, Chengzhen Wang. Surface subsidence law of filling with super-high-water material and skip mining, Shandong University of Science and Technology, 2011 (4) :1-8.

[3]Liu Hui, Kazhong Deng, Guichun Hu .

[4]Guangming Feng, Chengzhen Wang, Fengkai Li, Kaijun Jia. Research on Bag-Type Filling Mining with Super-High-Water Material [J], Mining and Safety Engineering, 2011 (12) :602-607.

[5]Fengyi Li, Xianrui Wang, Changliang Yao. Experimental study on filling mines under buildings with "three wastes" cemented material[J],Journal of Heilongjiang Institute of Science and Technology, 2013(11):527-530.

[6]Fengyi Li, Congfang Han, Guohua Zhang. Rock excavation and maintenance [M].Xuzhou: China University of Mining and Technology Press, $2003.189 \sim 224$. 